\title{
The Coronavirus Will Not Change the Long-Term Upward Trend of China's Economic Development
}

\author{
School of Economics and Management, Tongji University, Shanghai, China
}

\begin{abstract}
The author investigates the impact of COVID-19 and macro-policy adjustment on China's economic development. The aim is to describe the situation and trend of China's economic development before and after COVID-19. The research method is the comparative data analysis. The study shows that in response to COVID-19, the Chinese government, on the one hand, has accelerated its opening-up, taken the opportunity of fighting against the pandemic to provide medical assistance to and cooperate with other countries, and actively promoted the building of a community with a shared future for mankind and the process of globalization. On the basis of the Belt and Road Initiative and multilateral, regional, and subregional cooperation mechanisms such as the United Nations, Shanghai Cooperation Organization, BRICS (Brazil, Russia, India, China, South Africa), G20 (Group of 20), and APEC (Asia-Pacific Economic Cooperation), China and the Eurasian Economic Union began to cooperate more frequently and the trade relations between Japan, South Korea, and European developed countries became closer. Meanwhile, committed to building a global interconnection partnership, China actively participates in global economic governance and provides various public products. The Chinese government has proposed "Six Guarantees" on the basis of "Six Stability". In order to achieve the purpose of stabilizing foreign trade and expanding imports, China has imposed various measures to accelerate the liberalization and facilitation of international trade and investment, such as implementing the new version of the "Foreign Investment Law", establishing free trade zones, and promoting its experience and organizing international import expositions. Additionally, the Chinese government also implemented targeted fiscal and monetary policies, increased support for enterprises, especially small and medium-sized enterprises, and promoted the construction of "new infrastructure" and innovation of business model, which have formed the driving forces for the transformation of the economic development model in China from traditional business to cloud business, from traditional marketing to live streaming marketing, from traditional sales to online sales. The author concluded that China's adjustment of macro policies in response to COVID-19 was effective and played an important role in the resumption of production and life, stabilizing foreign trade activities, releasing domestic demand and promoting stable and sustained growth of the economy.
\end{abstract}

Keywords: COVID-19; new infrastructure; business models; stable and sustained growth; reform and opening up; digital economy; cloud business; live streaming marketing; macro-policy

For citation: Zhang X. The coronavirus will not change the long-term upward trend of China's economic development. Finance: Theory and Practice. 2020;24(5):15-23. DOI: 10.26794/2587-5671-2020-24-5-15-23

\section{INTRODUCTION}

Since China's economic development entered the "new normal"1 stage in 2014, although the economic growth rate has slowed, the real GDP growth was still very high, accompanied by more stable economic growth, more diverse growth momentum, more optimal economic structure, and more stable development prospects. In 2020, the outbreak of COVID-19 disrupted this state. This major pandem-

\footnotetext{
${ }^{1}$ The characteristics of the new normal economy are that the economic growth rate changes from high speed to medium speed. The economic structure has been constantly upgraded, and the driving force for economic growth has shifted from factors of production and investment to innovation.
}

ic has an unprecedented impact on the sustainable development of China and the global economy in terms of extent, depth and breadth. Although the Chinese government quickly took measures to bring the epidemic under control, China's economic development still faces huge challenges and risks in the post-epidemic era due to the normalization of epidemic prevention and control and many uncertainties. Therefore, while strengthening the prevention and control of the epidemic, the Chinese government adjusted the macroeconomic regulation in time and made more pragmatic and meticulous arrangements for economic and social development. A series of reform and opening-up 
measures introduced by the Chinese government is conducive to maintaining the long-term positive trend of economic development.

\section{THE PANDEMIC HAS CAUSED \\ A COMPREHENSIVE AND FAR-REACHING \\ IMPACT ON CHINA'S ECONOMY}

One of the severe consequences of the outbreak of the pandemic and its global spread on China's economic development is the deterioration of the external environment and increased uncertainty. First, the logistics obstruction caused by the draconian measures and the shutdown of a large number of enterprises has caused a huge impact on the deeply integrated global industrial chain and close collaboration. Many foreign trade companies have difficulty completing orders because of the shutdown. Europe and the United States, which are upstream of the global value chain, have been greatly affected, especially the high-tech products produced by these two regions. China is in the middle of the value chain and relies heavily on upstream products, which has led to a large negative impact on nearly $40 \%$ of its imported products. Second, the prevailing trend of counterglobalization, rising trade protectionism, cratering global economy, increasing unemployment worldwide and the sharply declining income has been precipitating the economic crisis, which caused steep declines in international trade. Third, the conflict between China and the United States has intensified. The United States has stigmatized and politicized China's epidemic, continuously promoted trade wars and technological wars, and even put forward the idea of "disengaging-fromChina”. Meanwhile, the United States has been constantly instigating conflicts of the affairs of Hong Kong, Taiwan and the South China Sea. All these have negatively affected China-US economic cooperation. These have greatly increased the pressure on China to develop an export-oriented economy, which has created an urgent need for China to seek breakthroughs.

The impact of the epidemic on China's domestic economic growth is direct and serious. During the epidemic, due to the draconian measures such as quarantines and lockdowns, restrictions on the movement of people, and corporate shutdowns, consumer demand has experienced a sharp decline in a short period, which has had a great impact on service industries such as commercial retail, tourism, catering, hotel, entertainment and aviation. Industry, construction, export and investment activities have also been affected to a certain extent. As a result, China's GDP contracted by 6.8 percent in the first quarter of 2020. Specifically, the added value of the primary industry decreased by 3.2 percent, the added value of the secondary industry decreased by 9.6 percent, and the added value of the tertiary industry decreased by $5.2^{2}$ percent. This is the first time China has experienced negative growth since the quarterly GDP data began to be published in 1992. However, the good news is that China has brought the epidemic under control in a short period. As the production of Chinese enterprises begins to resume, the impact of the epidemic on the economy will gradually weaken. China's economy contracted before growing in the first half of 2020. In the second quarter of 2020, GDP increased by 3.2 percent, turning from negative to positive. Total retail sales of consumer goods in May contracted by 2.8 percent year on year, 4.7 percentage points less than that in April, and increased by 9.8 percent year on year in June, 1.2 percentage points higher than the previous month with a 0.96 percent increase. ${ }^{3}$ However, due to the continued global spread of coronavirus and economic recession, the need to coordinate the control of the epidemic with normal life, and people's psychology and other factors, it will take a long time for China's economic growth to fully return to the state before the epidemic. The World Economic Outlook report released by the International Monetary Fund in April lowered the forecast of global GDP growth in 2020 from 3.3 percent in January to 3 percent. It is expected that China's GDP will grow by 1.2 percent, and by 2021 it will grow by 9.2 percent. ${ }^{4}$ It should be said that this expectation is more optimistic.

\footnotetext{
${ }^{2}$ National Bureau of Statistics of the People's Republic of China. URL: http://www.stats.gov.cn/ (accessed on 24.09.2020). ${ }^{3}$ National Bureau of Statistics of the People's Republic of China. URL: http://www.stats.gov.cn/ (accessed on 24.09.2020). ${ }^{4}$ I.M.F., IMF World Economic Outlook. URL: http://www.imf. org (accessed on 24.09.2020).
} 
THE LONG-TERM POSITIVE ECONOMIC TREND

\section{OF CHINA'S ECONOMY HAS NOT CHANGED}

Although the coronavirus has a short-term impact on China's economic growth, it has not changed the trend of China's long-term economic development. The reasons are as follows. First, China's current GDP per capita has exceeded $\$ 10,000$ and the urbanization rate has just reached $60 \%$. In the future, urbanization and metropolitanization will have growth capacity that can continue to provide impetus to economic growth. Second, China has a population of nearly 1.4 billion and a middle-income group of more than 400 million. It is the world's largest single market and the fastest growing market with huge potential. For example, between 2012 and 2018, more than half of the growth in the global luxury goods market came from China. In 2019, Chinese consumers drove 90 percent of the global luxury goods market growth and promoted 35 percent of luxury goods consumption [1, 2]. With the development of the Internet and logistics industry, consumption in rural China and third- and fourth-tier cities has also been stimulated. Although the pandemic and the cratering of the economy significantly affected the export business, as long as the domestic consumer market is fully stimulated, China's economy can be restored through its domestic demand in the short term or in the long run. Third, China has 900 million labor resources, of which 170 million are highly educated and skilled people, and there are more than 8 million university graduates each year. Economic growth is shifting from population-driven to talent-driven. Fourth, China has more than 120 million market participants, which are full of innovation and entrepreneurship. The "mass entrepreneurship and innovation" policy proposed by the Chinese government will further stimulate the enthusiasm and passion of innovation and entrepreneurship in the whole society, and promote the formation of more "new engines" of economic growth. Fifth, China has complete infrastructure, with high-speed railways, highway mileage, and the number of 10,000-ton berths in ports all ranking first in the world. China's industrial system is very sophisticated. It is the only country in the world that has been certified by the United Nations to have a complete industrial system. Internet, artificial intelligence, big data and other technologies that are widely used, will further expand into various fields, continue promoting economic development and innovation after the pandemic and drive e-commerce, e-government, virtual conference/ business, online teaching and other new business models into a new round of rapid development. At present, China's traditional industries account for less than $70 \%$ of the economy, and the prospects for digital industrialization and industrial digitalization are extremely broad. In 2018, China's total digital economy reached 31.3 trillion yuan, accounting for 34.8 percent of GDP, rising by 1.9 percentage points than that of the same period last year, and its contribution to GDP growth reached 67.9 percent, rising by 12.9 percentage points ${ }^{5}$ than that of the same period last year. Sixth, China will further promote Reform and Opening policy, actively participate in international economic coordination and cooperation, and maintain a sound external environment. These are conducive to further creating a more open, standardized and predictable business environment, enhancing China's comprehensive strength in participating in international competition, and forming a new advantage of openness and tolerance.

The Chinese economy still faces many problems. For example, the real economy is still in difficulty, private investment is growing slowly, potential financial risks are high, domestic development is unbalanced and inadequate, reform is arduous, and the international environment is uncertain. However, due to the continuous improvement of the economic structure, huge domestic demand, and constantly rising consumption the Chinese economy is seeking growth potential within itself and accelerating the pace of opening up to the outside world, to hold the bottom line of growth in the face of external shocks [3].

With the initial victory of the national battle against COVID-19, lifting restrictions and activating the economy as soon as possible on the basis of strengthening epidemic prevention and control has become the most important task in the post-COV-

${ }^{5}$ CAICT. White Paper on Data Infrastructure [R]. URL: http:// www.cbdio.com/image/site2/20191121/f42853157e261f (accessed on 24.09.2020). 
ID-19 era. Faced with unprecedented difficulties and challenges, the Chinese government has put forward the "Six Guarantees" policy (ensures security in jobs, basic living needs, operations of market entities, food and energy security, stable industrial and supply chains, and the normal functioning of primary-level governments) on the basis of "Six Stability" policy (ensures stability in employment, financial operations, foreign trade, foreign investment, domestic investment, and expectations). This is a timely adjustment made by the Chinese government in response to changes in the internal and external environment. At the macro level, the "Six Guarantees" policy did not deviate from the direction of "Six Stability", but made more pragmatic and detailed arrangements. For example, the "Six Stability" and the "Six Guarantees" both give top priority to employment. The goals of ensuring stability in financial operations, foreign trade, foreign investment, domestic investment and expectations in the "Six Stability" are consistent with those of ensuring operations of market entities, stable industrial and supply chains in the "Six Guarantees". The content of "ensuring industrial and supply chains" is aimed at dealing with the risks faced by domestic enterprises. The content of "Ensuring food and energy security" means trying to take precautions. The content of "ensuring the normal functioning of primary-level governments" is the minimum requirement and organizational guarantee for the society to resume as soon as possible. On the whole, "Stability" is the foundation and "Guarantee" is the bottom line. By ensuring "Stability" through "Guarantee" and seeking progress through "Stability", China will be able to overcome temporary difficulties and risks in the long run and lay a solid foundation for economic and social recovery and development [4].

Given the great uncertainties in the pandemic and the economic and trade situation, China has given top priority to ensuring employment and people's livelihood, which does not mean that China will give up economic growth. Instead, China is focusing on the quality of future economic development while addressing current issues and avoiding the negative consequences of past overly loose monetary policy. Economic growth is the foundation for stabilizing employment, ensuring people's livelihood, promoting consumption, and driving the market. In other words, the content of economic growth has been integrated into other economic and social development goals.

\section{INTENSIFYING OPENING UP \\ AND STABILIZING FOREIGN TRADE AND FOREIGN INVESTMENT}

Comprehensive and in-depth integration into globalization is an important reason for China's rapid economic development. In the face of the current situation of anti-globalization and prevailing trade protectionism, China will continue to promote allround opening up and develop an open economy at a higher level. This will not only create necessary conditions for China's high-quality economic development but also promote opening-up and cooperation among countries for common development worldwide.

First, China has stepped up opening-up to promote in-depth market-oriented reform through highlevel opening-up. First, in order to further promote and protect investment and encourage more foreign investment in modern agriculture, advanced manufacturing, high-tech and modern service industries, as well as in the central and western and northeast areas, China implemented the new version of the Foreign Investment Law of the People's Republic of China on January $1^{\text {st }}, 2020$, trying to eliminate restrictions on foreign participation, open up the service sector, especially the financial sector, cancel the foreign ownership restrictions and protect intellectual property rights. Second, in recent years, China has established pilot free trade zones in 18 provinces and cities, giving them greater autonomy in reform and innovation, and spreading their successful experience to the whole country. Based on that, with the focus on promoting the freedom and convenience of trade and investment, the whole island of Hainan will be built into a free trade port, making Hainan a special region. At the same time, Hainan will implement a "zero tariff" system for trade in goods, and trade in services will be open to foreign investors. Third, China has taken other measures, such as holding an international import Expo in Shanghai every year to expand imports and reduce tariff barriers.

In the plan entitled "The CPC Central Committee and the State Council to Promote and Improve the Socialist Market Economic System in the New Era" 
adopted on May 11, 2020, the Chinese government further proposed the goal of building a new open economic system of a higher level and promoting reform and development with "opening up". All this shows that, no matter how the international environment may change, China will unswervingly push forward its opening-up policy and make greater efforts to do so.

Second, China has actively promoted the Belt and Road Initiative and cooperation with the Eurasian Economic Union. Since the Belt and Road Initiative was put forward in 2013, China has received response and support from an increasing number of countries. The sudden outbreak of COVID-19 has had a huge impact on the construction of the Belt and Road Initiatives, but it has also encouraged China to adopt a more diversified model of cooperation. For example, as the first country hit by COVID-19 and the first to contain it, China has increased its assistance to countries that cooperate to build the Belt and Road Initiative. This not only provides support "made in China" for the global fight against the epidemic, but also further strengthens cooperation with countries that are critical to the Belt and Road Initiatives, including Russia, Pakistan and Iran. The focus of the Belt and Road Initiatives has also shifted from energy and infrastructure to health care and digital telecommunications. The sanctions imposed by the United States and the Western world on Russia have even brought China and Russia closer to each other on the basis of a solid, traditional relationship. China and Russia have reached agreement on the establishment of the Eurasian economic partnership and agreed to promote cooperation among the Belt and Road Initiatives and the Eurasian Economic Union, and to take advantage of SCO (Shanghai Cooperation Organization) to open up space for common economic development on the entire Eurasian continent $[5,6]$. These are not only in line with China's proposal of consultation, contribution and shared benefits of the Belt and Road Initiatives and building a new type of international relations and a community with a shared future for mankind, but also in broad agreement with Russia's proposal of a greater Eurasian partnership in handling the basic principles of international relations and promoting regional economic integration and development. In the near future, Eurasia will become an alternative to western political and economic system which is totally different from western forms of economic development mode and build an economic partnership among ASEAN and the Regional Comprehensive Economic Partnership (RCEP), the Eurasian economic union, the economic cooperation organization and the EU. Meanwhile, these countries and organizations will communicate with each other through the cooperation of the hardware infrastructure of six economic corridors and three blue economic passages. ${ }^{6}$ Trade and investment facilitation will be achieved through the cooperation of software infrastructure such as regulations, standards and laws, with the ultimate aim of building a globally oriented free trade area of high standards throughout Eurasia.

Third, China actively promotes the construction of the community with a shared future for mankind, participates in global economic governance and the supply of public products, stimulates the stagnant globalization process. In the first place, China cooperates with the countries suffering from the COVID-19 to carry out medical assistance during the period of fighting the epidemic, and promotes international collaboration with other nations. As of May $31^{\text {st }}, 2020$, Chinese local governments, enterprises, private organizations, and individuals have donated anti-epidemic materials to more than 150 countries, regions, and international organizations through various channels. At the same time, they also have provided anti-epidemic medical supplies to 82 countries, the World Health Organization and the African Union. China has compiled a complete set of technical documents such as the latest treatment regimen, prevention and control plan, and shared it with 180 countries and more than 10 international and regional organizations in a timely manner. ${ }^{7}$ The

\footnotetext{
${ }^{6}$ The "Six Economic corridors" refers to The China-MongoliaRussia, new Eurasian Land Bridge, China-Central Asia-West Asia, China-Indochina Peninsula, China-Pakistan and Bangladesh-China-India-Myanmar Economic Corridors. The "Three Blue Economic Passages" refers to the blue economic passage that connects China, the Indian Ocean, Africa and the Mediterranean Sea, the passage that connects China, Oceania and the South Pacific Ocean, and the passage that connects China and Europe via the Arctic Ocean.

${ }^{7}$ The State Council Information Office of the People's Republic of China. Fighting Covid-19, China in Action. June, 2020. URL: http://www.scio.gov.cn/ztk/dtzt/42313/43142/index.htm (accessed on 24.09.2020).
} 
Chinese government promises that the vaccine of coronavirus will be used as a global public product once developed and put into use. Beyond that, China has actively participated in global economic governance and the provision of public products through multilateral, regional, and subregional cooperation mechanisms such as the United Nations, Shanghai Cooperation Organization, BRICS, G20, APEC, etc., building a global interconnection partnership based on the Belt and Road Initiative. At the same time, China has also strengthened trade relations with developed countries such as Japan, South Korea, and Europe, and has included many developing countries in the globalization process. China's increasing economic strength, huge market, and increasingly open and free economy have provided guarantees for participating in global economic governance and the supply of public products and promoting the process of globalization. In fact, China has become a dominant force in building a community with a shared future for mankind and promoting the process of globalization.

China is opening wider to the outside world. By promoting win-win cooperation with all parties, China has stabilized the industrial and supply chains, made its economic development more resilient and potential, and stabilized foreign trade and investment. The effects of these measures start to show and will continue expanding. In the first half of 2020, the actual use of foreign capital in China was 472.18 billion yuan, decreasing by 1.3 percent compared with the same period last year (excluding banking, securities and insurance sectors, as follows). Among them, the second quarter growth is 8.4 percent yearon-year, compared with the 10.8 percent decline in the first quarter, which shows a significant recovery. In June, actual foreign investment reached 117 billion yuan, increasing by 7.1 percent year-on-year, which has shown growth for three consecutive months. Expectations and confidence in foreign investment are stable and growing gradually, and there has been no large-scale withdrawal of foreign investment in China. China's exports and imports fluctuated in the first quarter of 2020, stabilized in the second quarter, and went from negative to positive in June. The value of imports and exports in the first half of the year was 14.24 trillion yuan, decreasing by 3.2 percent year-on-year, with imports and exports falling 3.3 percent and 3 percent respectively, and both of the indicators are better than expected. ${ }^{8}$

\section{STIMULATING DOMESTIC DEMAND WITH NEW INFRASTRUCTURE AND INNOVATIVE BUSINESS MODELS}

At present, as one of the Troika, consumption has been the primary driving force of China's economic growth for six consecutive years. In 2019, China's dependence on foreign trade decreased from 65 percent at the historical peak to less than 33 percent, among which the dependence on exports decreased from 35 percent at the historical peak to less than 18 percent, and the contribution of consumption to GDP growth increased to 57.8 percent. ${ }^{9}$ The contribution of consumption to economic growth in the first half of 2020 has been raised to 60.1 percent. ${ }^{10}$ China has a high savings rate. China's savings rate, which was 50 percent a decade ago, is now 45 percent, still the highest in the world and the potential for investment and consumption is huge. China's economic growth model has begun to shift from exports and investment to domestic consumption. Regardless the perspective of shortterm supply and demand balance or medium and long-term economic growth, the importance of boosting consumption for macroeconomic stability and healthy development is far greater than that of stimulating investment. However, the outbreak of COVID-19 has had the biggest impact on consumption and the longest period of negative impact. From January to April in 2020, the total retail sales of consumer goods dropped by 16.2 percent. Therefore, expanding domestic demand is the key to bringing production and people's life back to normal as soon as possible and promoting economic growth.

To stimulate domestic demand, it is necessary to expand public and private consumption. The Chinese government has expanded public consumption mainly through a proactive fiscal policy and a

\footnotetext{
${ }^{8}$ Ministry of Commerce of the People's Republic of China. URL: http://www.mofcom.gov.cn/ (accessed on 24.09.2020).

${ }^{9}$ National Bureau of Statistics, PRC. URL: http://www.stats. gov.cn/ (accessed on 24.09.2020).

${ }^{10}$ National Bureau of Statistics, PRC. URL: http://www.stats. gov.cn/ (accessed on 24.09.2020).
} 
prudent, flexible and appropriate monetary policy, combining short-term stimulus with long-term planning. According to the Government Work Report of the State Council for 2020, the deficit-to-GDP ratio will rise from 2.8 percent last year to more than 3.6 percent in 2020, with a deficit of 3.76 trillion yuan and the issuance of 1 trillion yuan of special government bonds to combat the pandemic. This is the first time China's fiscal deficit has exceeded 3 percent, the highest on record. These fiscal expenditures are mainly used for upgrading old cities and urban renewal, improving public service facilities such as medical care and education, and improving the environment, and providing cash or consumption vouchers to low-income and unemployed people to ensure their basic living expenses. The Chinese government has also reduced the operating risks of small and medium-sized enterprises and stabilized the income and employment of residents by reducing taxes and fees and fiscal subsidies, in conjunction with monetary policies such as interest rate cuts, targeted RRR cuts and interest rates on re-loans and excess reserves cuts.

Building new infrastructure will not only stimulate investment demand but also provide important support for China's economic and social prosperity in the future. The old infrastructure projects, mainly railways, highways, airports, ports and water conservancy facilities, are characterized by large investment scale, long construction cycle, obvious short-term stimulus effect and slow return on investment. Relatively speaking, new infrastructure projects focus on new technologies, which emphasize stable growth and employment rather than strong stimulus, and focus on "use" rather than "construction". Their purpose is to promote the development of new forms of business, new industries and new services through informatization, intelligentization and digitization. ${ }^{11}$ As a result, new infrastructure can not only rapidly expand investment demand, stimulate the economy and create more jobs in the short term but also become the most important engine of high-quality economic development, unleash economic growth potential and enhance international competitiveness.

${ }^{11}$ State Council of the People's Republic of China. Opinions on Accelerating the Improvement of the Socialist Market Economy in the New Era. People's Daily. 19.05.2020(06).
They will contribute a lot to improving production and consumption conditions, enhancing the efficiency of transportation, information exchange and business cooperation, and promoting the development of new industries and fields.

To stimulate domestic demand, China relies mainly on business model innovation rather than on cash and consumer vouchers. The innovation of the business model can not only stimulate consumption in the short term but also form a long-term mechanism to promote consumption growth, making it a new engine to lead consumption, promote industrial structure upgrading and boost economic growth.

In addition to income, consumption is also affected by psychology, willingness, scene, convenience, and other factors. Although people have a strong tendency to consume explosively after the epidemic, it is not feasible to start offline consumption on a large scale in the short term due to the risk of personal health and the need of social epidemic prevention and control. To this end, efforts can be made on the supply side to promote the innovation of business models of brick-and-mortar stores, so as to realize as soon as possible the transformation from traditional business to cloud business, traditional marketing to live streaming marketing, independent development to shared platforms, indoor sales to outdoor sales [7-9].

The transformation from traditional business to cloud business is to shift from offline sales to the combination of online and offline sales, so as to realize the deep integration of digital upgrading of goods, transactions, data and services with online and offline sales. For example, stimulating consumption through online sales, TV sales, online discounts and promotions, online shopping festivals; conveying relevant information through the live broadcast of museums, art galleries and amusement parks and attracting people through livestream culinary classes, etc. These measures, together with the issuance of consumption subsidies and discount vouchers, can effectively promote the release of consumption potential. Pinduodo (NASDAQ: PDD) has seen an average of 65 million packages in transit per day since May, increased by 30 percent from March, according to the company's 2020 Q1 financial report. Shanghai has also launched the "May 5th Shopping Festival \& 
Quality Life and Live Week" to prepare itself as "the most live-streamed city". Pinduoduo spent $\$ 2.5$ billion on consumer subsidies during the campaign. In addition, many foreign trade enterprises have turned to live broadcasting for domestic sales, which has also achieved good results. The 127th China Import and Export Fair, which opened on June 15, was also put on the "cloud" for the first time for live broadcast sales, breaking the original time and space boundaries and ended up attracting a large number of customers.

The transformation from traditional marketing to live streaming marketing aims to promote consumption by non-sales people, including online celebrity promotion, the offline launch of a small discount of brand-name products and best-selling products to attract customers and drive sales of other products, as well as online and offline demonstration consumption by government officials, celebrities and ordinary people. The live streaming of mayors is very popular across the country. For example, data released by Pinduoduo shows that until May 14th, Pinduoduo has been more than 425 million kilograms of agricultural products sold in its "Mayors' livestreaming rooms", and 113,000 new enterprises aiming to "shift from foreign trade to domestic sales", with the turnover exceeding 5.89 billion yuan. Dong Mingzhu, Chairwoman of Gree Electric Appliances, started live streaming with 30,000 offline stores, and explored the new retail form of three key links: online traffic, offline stores and supply chain.

The transformation from independent development to shared platforms means that previously independent production and operation enterprises, especially small and medium-sized enterprises and individual producers and operators, take the initiative to integrate into the ecosystem of shared platform, take advantage of their own strengths and resources to carry out collaborative operations, and provide unique and convenient products and services to consumers. "Shared employees" in various e-commerce platforms and catering enterprises, as well as Sinopec's vegetable and coffee businesses are typical examples of this model.

The transformation from indoor sales to outdoor sales means improving and expanding the places where goods and services are consumed, and standardizing the development of the stallholder economy, roadside catering, outdoor entertainment, and night economy. These business entities can promote the recovery of market sentiment, increase employment, and stimulate consumption on the premise of no large-scale group consumption behavior. The reason lies in that these commercial entities meet the needs of consumers, facilitate their purchase and make them prone to random or impulsive consumption. In the past, most of these commercial activities were prohibited because of their negative impact on the appearance of the city, damage to environmental sanitation, violation of fair competition, occupation of public resources such as roads, lack of permits, tax evasion and other reasons. Now, the development of the street economy and the small shop economy start to be encouraged across the country. Shanghai launched the first Shanghai Nightlife Festival on June 6th, featuring more than 180 activities including Shanghai Bar Festival, late-night dining Festival, late-night entertainment, late-night show, and latenight reading.

China has a large population, low labor cost, high Internet penetration, developed logistics, convenient delivery and the world's best online shopping infrastructure. Even in remote villages, mobile networks and logistics are well spread. These provide good conditions for business model innovation. China has a wide range of commodities at cheap prices. The innovation of the business model can become a new carrier and engine to lead consumption, promote industrial structure upgrading, and drive economic growth. Thanks to the innovation of the above business model, China's online consumption showed a good development trend during and after the epidemic. China's express delivery volume and revenue reached 7.38 billion yuan and 77.1 billion yuan in May, increased by 41 percent and 25 percent year on year, respectively, hitting new peaks since February 2018, according to data released by the National Bureau of Statistics of China. ${ }^{12}$

\section{CONCLUSION}

From the international environment perspective, in the post-COVID-19 era, the center of gravity of the world economy will continue to shift eastward to

\footnotetext{
${ }^{12}$ National Bureau of Statistics, PRC. URL: http://www.stats. gov.cn/ (accessed on 24.09.2020).
} 
Asia, and multipolar cooperation will become a new trend in economic globalization. Meanwhile, the Fourth Industrial Revolution, marked by big data, artificial intelligence and digitalization, will become a new engine of economic growth. All this has created conditions for the recovery and development of the global economy and China's economy in particular.

Due to reform and opening-up, China has now escaped the middle-income trap. With the sound foundation of China's economic development, the government can timely adjust its macro policies in accordance with changes in the domestic and international environment. Policy adjustments are highly flexible and the economy is resilient. Despite the huge impact of COVID-19 on the sustainable development of China's economy and the uncertainty of the external environment, China has taken strong and effective measures to cope with the epidemic and economic downturn and has become the first economy in the world to emerge from the epidemic and gradually return to normal operations. At the same time, the Chinese government has introduced a series of economic stimulus policies and measures aimed at restoring production and livelihood, stabilizing foreign trade, and stimulating domestic demand. These measures have produced good results and provided new support for China's economic stability and sustainable development. The emergency of COVID-19 and "antiglobalization" has not changed the general trend of China's economic and social development from rapid growth to high-quality development. On the contrary, it has provided China with valuable opportunities for a broader opening to the outside world and pursuing innovative development. All these factors will give a strong impetus to China's economic development and ensure its stable and sustained development.

\section{REFERENCES}

1. Jinping Xi. Seeking sustainable development and building Asia-Pacific dream together. People's Daily. 10.11.2014(02). (In Chinese).

2. Bain-Altagamma. Luxury goods worldwide market study. Fall-Winter 2019. URL: https://www.bain.cn/news_info. php?id=945 (accessed on 24.09.2020). (In Chinese).

3. Shi Cheng. Inward development: China's economic outlook for the second half of the year. 2019. URL: http://opinion. caixin.com/2019-07-04/101435375.html (accessed on 24.09.2020). (In Chinese).

4. Lifan Xu. From "six stability" to "six guarantees", bottom line thinking and the sense of hardship were highlighted. The Beijing News. 20.04.2020(A02). (In Chinese).

5. Li Xin. The Belt and Road initiative will help China open up a common Eurasian economic space. Chinese Social Sciences Today. 14.12.2017(04). (In Chinese).

6. Li Xin. The Belt and Road Initiative constitutes an Asia-Europe economic partnership. Shanghai: Shanghai Far East Publishers; 2019. (In Chinese).

7. Chaoxian G., Jiaqi W., HaorongL. Studies on how new infrastructure empowers high-quality development of China's economy. Journal of Beijing University of Technology (Social Sciences Edition). URL: https://kns.cnki.net/kcms/detail/ 11.4558.G.20200628.1127.008.html (accessed on 24.09.2020). (In Chinese).

8. Zhang Xin. It is necessary to give consideration to both short-term stimulus and long-term plan to boost consumption. Shanghai Wenhui Daily. 02.04.2020(8). (In Chinese).

9. Wei W. Treat the impact of the epidemic in a dialectical manner to better promote innovative development. Economy. 2020;(02):35-37. (In Chinese).

\section{ABOUT THE AUTHOR}

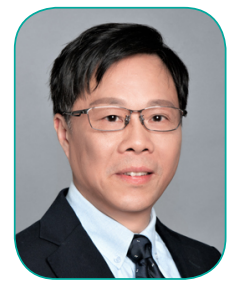

Xin Zhang - Ms. Sci. (Econ.), Assoc. Prof., School of Economics and Management, Tongji University, Shanghai, China

zhangxin@tongji.edu.cn

The article was submitted on 02.08.2020; revised on 20.08.2020 and accepted for publication on 22.08.2020. The author read and approved the final version of the manuscript. 